\title{
Recombinant Human Interleukin-15
}

National Cancer Institute

\section{Source}

National Cancer Institute. Recombinant Human Interleukin-15. NCI Thesaurus. Code C1545.

A recombinant agent that is chemically identical or similar to the endogenous form of the human cytokine interleukin-15 (IL-15) with immunomodulating activity. IL-15, secreted by mononuclear phagocytes (and some other cell types) following viral infection, regulates $\mathrm{T}$ and natural killer cell activation and proliferation. This cytokine induces activation of transcription activators STAT3, STAT 5, and ST AT 6 via JAK kinase signal transduction pathways in mast cells, T cells, and dendritic epidermal T cells. IL-15 and interleukin-2 (IL2) are structurally similar and share many biological activities; both may bind to common hematopoietin receptor subunits, negatively regulating each other's activity. CD8+ memory T cell number has been shown to be regulated by a balance between IL-15 and IL-2. 